\title{
La acción ritual indígena ante el sistema mundial: ritos marubo de curación, solidaridad y resistencia
}

\author{
Javier RUEDAS \\ University of New Orleans \\ mranthro@grandecom.net
}

Recibido: 10 de enero de 2013

Aceptado: 24 de enero de 2013

\begin{abstract}
RESUMEN
Este ensayo examina el papel de los rituales y discursos ceremoniales marubo en los enfrentamientos con el sistema global en sus aspectos político-económicos. Durante y después de la fiebre del caucho (aprox. 1890-1920), los antepasados de los marubo migraron desde sus ubicaciones previas hasta un nuevo lugar en las cabeceras de los riachuelos de la cuenca del Yavarí, aislándose de la participación en las actividades económicas del comercio del caucho. Ahí, construyeron una alianza entre miembros de diferentes etnias pano. La alianza fue mediada por el desarrollo de un nuevo sistema ceremonial centrado en los ritos de curación y las fiestas, ambas categorías justificadas por una filosofía de antiviolencia, intercambio y cuidado mutuo, explícitamente pensada para sobrevivir a la fiebre del caucho. Con el tiempo, la alianza se convirtió en fusión étnica, dando lugar a una nueva identidad étnica. A finales del siglo XX, los marubo se enfrentaron a una reintegración al sistema global, a través de la incorporación a la organización burocrática del estado brasileño. Otra vez crearon una alianza interétnica, la organización indígena CIVAJA. Esta alianza fue mediada por las reuniones del movimiento indígena y sus discursos sobre autonomía y poder indígena. El ensayo concluye mostrando un ejemplo concreto del uso del sistema ceremonial marubo para invertir las relaciones de poder entre indígenas y burocracia.
\end{abstract}

Palabras clave: Marubo, caucho, movimiento indígena, discurso ceremonial, ritual, historia, identidad étnica.

\section{Indigenous Ritual Action Versus the World System: Marubo Rites of Healing, Solidarity, and Resistance}

\begin{abstract}
This paper examines the role of Marubo ritual and ceremonial discourse in confrontations with the world system in its politico-economic aspects. During and after the rubber boom (c. 1890-1920), the ancestral Marubo migrated from their previous locations to a new home in the headwaters of the small rivers of the Javari River, isolating themselves from participation in the rubber economy. There, they built an alliance between distinct Panoan ethnic groups. The alliance was mediated by the development of a new ceremonial system centered on healing rituals and feasts, both categories justified by an ethic of anti-violence, exchange, and mutual care, explicitly thought out as a strategy for surviving the rubber boom. Over time, the alliance became an ethnic fusion, giving rise to a new ethnic identity. At the end of the twentieth century, the Marubo faced reintegration to the world system through incorporation into the Brazilian bureaucracy. Once again they created an interethnic alliance, the indigenous organization CIVAJA. This alliance was mediated by the indigenous movement's political meetings and its discourses on indigenous autonomy and power. The essay concludes by showing a concrete example of the use of the Marubo ceremonial system to invert power relations between indigenous peoples and national bureaucracy.
\end{abstract}

Key words: Marubo, rubber, indigenous movement, ceremonial discourse, ritual, history, ethnic identity.

Sumario: 1. Contexto histórico: la fiebre del caucho. 2. La alianza interétnica. 3. Los ritos de curación. 4. Las fiestas. 5. Las reuniones. 6. Las radios. 7. La acción ritual en la transformación de relaciones de poder. 8. Conclusión. 9. Referencias bibliográficas.

En la Amazonía, los procesos de integración forzada de pueblos indígenas en el sistema mundial han dado lugar al desarrollo de nuevas formas de acción social con las cuales estos pueblos se proponen ejercer algo de control sobre las fuerzas políticoeconómicas que amenazan con destruirlos. En contextos históricos de transformación 
social acelerada, los sistemas simbólicos amazónicos se convierten así en instrumentos de poder y los discursos median en transiciones entre ordenamientos de relaciones sociales, particularmente las desconexiones de y reconexiones al sistema mundial (Whitten 2003). Cantores, oradores y poetas indígenas reconfiguran antiguos géneros de discurso y así crean nuevos sentidos e interpretaciones de la tradición, un proceso que ha sido llamado recontextualización (Graham 1995; Oakdale 2009). La recontextualización es una de las claves del desarrollo de nuevas identidades étnicas amazónicas. En este ensayo, examino la historia de los marubo del río Yavarí en el siglo XX para mostrar cómo han usado los discursos ceremoniales, nuevos y recontextualizados, para hacer frente a la integración forzada en el sistema mundial.

La historia de los marubo en el siglo XX es de desconexión del sistema mundial a principios de siglo, seguida décadas más tarde por una reconexión. En ambos casos, los marubo crearon alianzas interétnicas para sobrevivir y prosperar ante la amenaza del etnocidio y la pérdida de control sobre sus propios destinos. En ambos casos, antiguos discursos ceremoniales recontextualizados y nuevos discursos introducidos mediaron en la transición entre sistemas de relaciones sociales. A comienzos del siglo $\mathrm{XX}$, los ancestros de los marubo juntaron antiguos géneros de discurso ceremonial en un nuevo sistema que medió una alianza interétnica, sentando las bases de una nueva identidad étnica. Los líderes abogaron por la desconexión del sistema mundial y un foco social en fiestas formales, ritos de curación y performance de mitos cantados; la alianza interétnica facilitó la supervivencia demográfica y se convirtió en fusión de etnias. A finales del siglo XX, la incorporación a la burocracia nacional brasileña dio lugar a nuevas formas de discurso y ceremonia que mediaron en una nueva alianza interétnica creada para invertir las relaciones de poder entre indígenas y burocracia. Describiré ambos procesos históricos vistos desde la perspectiva marubo, concluyendo con un ejemplo concreto del uso del sistema ceremonial para dar un vuelco a las relaciones de poder entre indígenas y no-indígenas en el Yavarí.

\section{Contexto histórico: la fiebre del caucho}

Los pueblos pano de la cuenca del Yavarí se enfrentaron por primera vez a la integración forzada en el sistema mundial durante la fiebre del caucho, que empezó en esta región aproximadamente en 1890. Hasta entonces, ningún producto del Yavarí ofrecía suficiente lucro para compensar el coste de la explotación sistemática (Melatti 1981; Coutinho 1993). Sin embargo, a partir del auge final de los precios del caucho, coincidiendo con el aumento de demanda relacionado con la producción de neumáticos para la modernización del sistema de transporte occidental, muchos miles de peones del caucho llegaron a extraer el caucho del Yavarí y de sus afluentes (Weinstein 1983). Para asegurar el acceso a los árboles que abastecían el látex para el caucho, los patrones del caucho obligaron con violencia a los pueblos pano a mudarse o incorporarse al sistema como mano de obra o como patrones de bajo nivel (Montagner y Melatti 1975; Coutinho 1993).

Visto desde la perspectiva de las historias orales marubo, la fiebre del caucho fue un genocidio brutal. Estas historias cuentan al menos ocho masacres y otros encuentros violentos, muchos con el resultado de la destrucción o dislocación de pueblos indíge- 
nas y pérdidas demográficas de hasta el $90 \%$. Está claro por los relatos tanto indígenas como no-indígenas que muchos pano del Yavarí colaboraron con el comercio del caucho, pero las historias orales marubo asocian esa colaboración con la violencia. Ante tal situación, los antepasados de los marubo escogieron huir y aislarse.

A este respecto, un evento clave en la historia de los marubo fue el rapto de la madre de Domingos por caucheros peruanos. En un afluente del alto Yavarí, el líder ninawavo, Tomás, había aprobado las relaciones comerciales con los caucheros del Yavarí (Montagner y Melatti 1975: 22). Su cuñado, Chico Tuxaua, organizaba grupos de trabajo para extraer látex y llevarlo al Yavarí. De acuerdo con el relato de un hijo de Domingos, Chico se peleó con el patrón y éste raptó a una de sus esposas, embarazada, y a su nieto Ernesto. Entonces Tomás decidió mudarse con su familia lejos del Yavarí, a las cabeceras del Maronal (un afluente del Curuçá del lado del Ituí) llevándose a su hijo, el futuro líder João Tuxaua. Chico no lo siguió hasta que, siete años más tarde, sus hijos recapturaron a los raptados, ahora incluyendo a su joven hijo Domingos, que había sido criado entre los peruanos. Entonces, Chico llevó a su familia a vivir junto a Tomás. Fue por esa época que Tomás cantó para dispersar a los nawa (no-indígenas), evento contado por su nieto José:

«Entonces los indios fueron a las cabeceras del Maronal. Sólo había las cinco malocas de Dionísio, Ernesto, Júlio, Domingos, y João Tuxáua. Eran pocos, pero les gustaba hacer fiestas. Hacían el akoya [ver Cuadro 2], pero eran tan pocos que las mujeres tenían que ayudar a cargar el ako. Entonces mi abuelo, Tomás, cantó hacia una taza de jugo de genipa [la taza directamente debajo de la boca al cantar]. Fue a poner esa genipa en todos los lugares donde estaban los blancos, y en todos los ríos y riachuelos para que las aguas la lleven a los nawa [extranjeros, blancos]. Entonces, los nawa se fueron, y por mucho tiempo de nuevo sólo había indios, hasta que vinieron los madereros».

En las historias marubo, se repite con frecuencia el motivo de un conflicto o masacre, seguido de una invitación por parte de João Tuxaua a los sobrevivientes a que se muden a vivir en las cabeceras con él (Ruedas 2001; Welper 2009). La familia de Júlio murió masacrada por peruanos, dicen, y João Tuxaua invitó a Júlio a vivir con él. Casi toda la familia de Dionísio murió, salvo él y sus hermanas, y João Tuxaua los encontró e invitó a vivir con él. De esta forma, se formó lo que llamaré el círculo ( a turma) de João Tuxaua, ese pequeño grupo de líderes pano afines que crearían en conjunto el sistema ceremonial marubo. Cuenta José:

«Mi padre se echaba en la hamaca encima del ako y los espíritus llegaban. Le llevaban y enseñaban todo. Le enseñaron los nombres y los orígenes de todas las cosas. Cuando volvía, se lo contaba a la gente, o lo cantaba. Mi abuelo también era curador, pero no tan fuerte como mi padre. Mi padre fue el que juntó en un lugar a todos los marubo que no querían pelear. Él curaba a la gente, cantaba todo el tiempo, hacía fiestas. Las mujeres le querían mucho. Tuvo muchos niños. Aquellos líderes que pensaban como él, como Domingos, Julio y Ernesto, fueron con él. Los otros, los marubo bravos, siguieron peleándose con los nawa y entre ellos mismos. Desaparecieron. Mi padre nunca paraba de hablar. Siempre estaba contando historias. Bebía ayahuasca casi todas las noches, iba a todas las malocas, cantando, y todo el mundo escuchaba. Así aprendimos a cantar, mis hermanos y yo y los hijos de Domingos». 
Esta es, en breve, la interpretación histórica que subyace en muchos aspectos del sistema ceremonial marubo. Los bravos se peleaban, se mataban y se raptaban entre ellos, había siempre hambre porque nadie podía hacer plantíos ni cazar ni organizar fiestas. Pero entre el círculo de João Tuxaua, lejos de las relaciones comerciales con los nawa, tenían fiestas. Plantaban, cazaban, cantaban, curaban, cuidaban el uno del otro, se casaban entre ellos y tenían muchos niños y barrigas llenas. Todos los «que pensaban como él» creían en el valor de las fiestas y de los ritos de curación y estaban dispuestos a participar en ellos. Este fue el contexto para el desarrollo del sistema ceremonial marubo.

\section{La alianza interétnica}

Los antepasados de los marubo formaron una alianza interétnica para sobrevivir y prosperar en medio de la violencia de la fiebre del caucho. Los pano que se juntaron en la cabecera del Maronal a principios del siglo XX no tenían una única identidad étnica, sino múltiples identidades y lenguas. Sin embargo, compartían un universo simbólico abarcando motivos mitológicos y categorías de parentesco, símbolos que facilitaron la fusión de diversos grupos en uno. El círculo de João Tuxáua negoció sus diferencias, alcanzó una unidad simbólica que no había existido previamente y formó un nuevo sistema social. El sistema ceremonial, innovador y continuista al mismo tiempo, medió esta creación social.

Los marubo cuentan a menudo que la lengua que hablan hoy es la lengua de los shainawavo, pero que sus antepasados hablaban otra lengua, que llaman «asánkiki.» Un hijo de Domingos me contó en 2009 que su padre había sido criado hablando el asánkiki, y me dio ejemplos del idioma, reconociblemente pano pero con vocabulario, frases, y entonación diferentes. Welper (2009: 62) dice que la madre de Domingos, cuyo rapto precipitó la migración a las cabeceras del Maronal, era hermana de un hombre raptado por Chico Tuxaua, de una etnia diferente de la de Chico. Dice también que varias hermanas de aquel hombre se habían casado con la familia de Chico. De este modo, vemos aquí indicios de una primera alianza interétnica, entre los satanawavo y rovonawavo, familia de Chico, y los ranenawavo y ninawavo, familia de Domingos y Tomás, y cuya relación original de cautivos se transformó en relación de aliados. Esta alianza multilingüe se mudó al Maronal, sentando así la base de la futura etnia marubo. El marubo contemporáneo se asemejaría más a la lengua hablada por la familia de Chico. Además, es común oír que los inonawavo, identidad que dominaba la zona entre el Pardo y el Yavarí, hablaban otra lengua. Así, existían múltiples identidades pano en diversas zonas de la cuenca del Yavarí, juntándose algunos de estos grupos bajo el liderazgo del círculo de João Tuxaua en las cabeceras de los riachuelos entre el Curuçá y el Ituí. Una de las claves de esta alianza interétnica fue la fusión de estos grupos en un universo de parentesco, apoyándose en las categorías compartidas del parentesco pano.

Entonces, fue fundamental para la alianza interétnica fundacional marubo que todos los miembros de la alianza pudieran pertenecer, en relación a todos los otros miembros, a una de las cuatro categorías básicas de parentesco. El sistema Kariera 


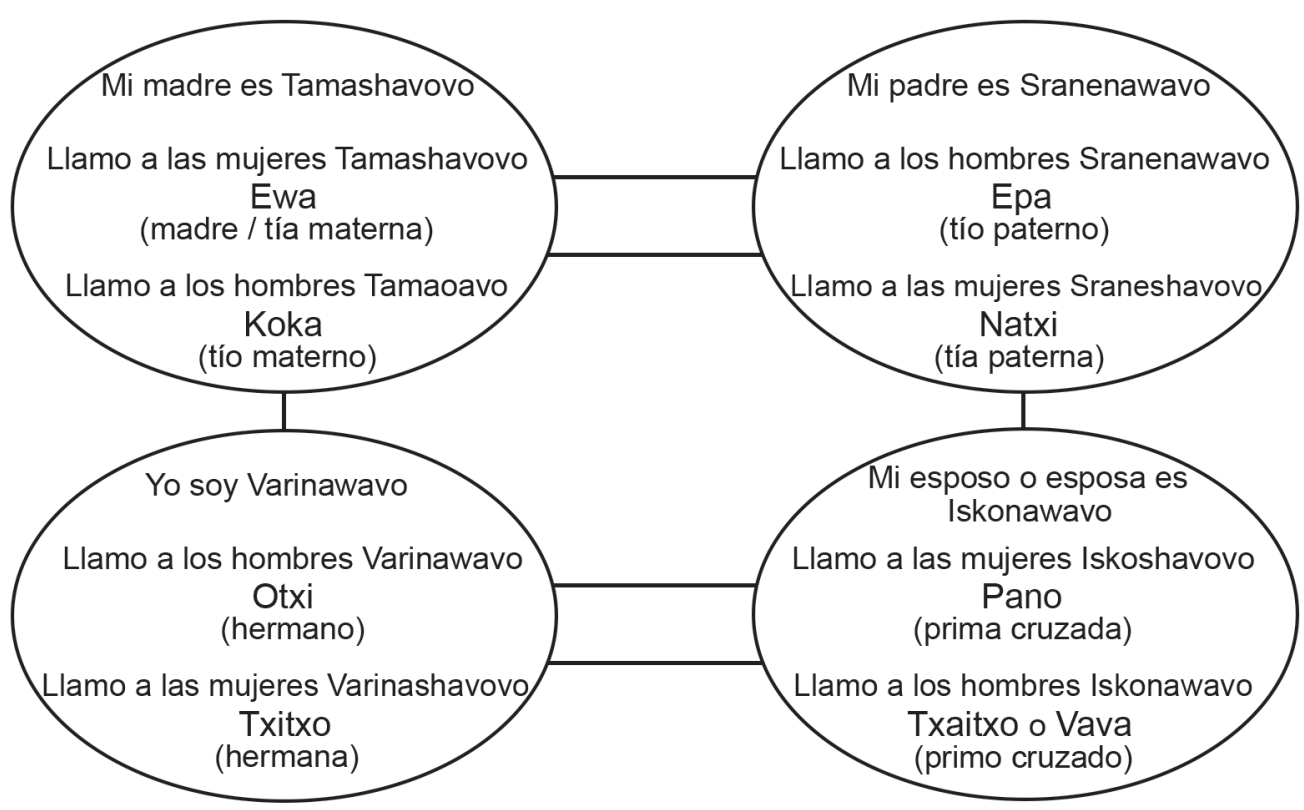

Figura 1: El universo de parentesco marubo. En contraste con el sistema Dravidiano, donde la mitad del universo de parientes son afines y la mitad consanguíneos, en el sistema Kariera de los marubo, la consanguinidad se extiende a las tres cuartas partes y sólo la cuarta parte son afines.

de los pano (Melatti 1977; Kensinger 1995) facilita esta identificación de otros pano como parientes. En el dominio semántico del parentesco, todos los pano comparten un mismo sistema simbólico (Cuadro 1). En casi todos los sistemas de parentesco pano, aplicar los términos de parentesco genera cuatro categorías fundamentales de parientes (Figura 1). Casi todos los pano comparten este esquema y los cognados de nombres de categorías. Las diferencias interétnicas no yacen en las categorías de parentesco, sino en las teorías culturales sobre las relaciones apropiadas entre categorías. En el caso marubo, la clave es que cada categoría de parentesco es un grupo social nombrado.

Una característica básica de la familia pano es la proliferación de grupos sociales nombrados, típicamente con nombres acabando en -nawavo ('gente'; Keifenheim 1990; Erikson 1996). Estos grupos tienen significados sociales diferentes en dife-

Cuadro 1: Cognados de categorías de parentesco en algunos idiomas pano.

Es notable que casi todas las categorías son compartidas entre los pano excepto las primas cruzadas (Melatti 1977; Kensinger 1995; Eakin, Laurialt y Boonstra 1986).

\begin{tabular}{llllllllc}
\hline & Hermano & Hermana & $\begin{array}{c}\text { Prima } \\
\text { cruzada }\end{array}$ & $\begin{array}{c}\text { Primo } \\
\text { cruzado }\end{array}$ & $\begin{array}{c}\text { Tío } \\
\text { paterno }\end{array}$ & $\begin{array}{c}\text { Tía } \\
\text { paterna }\end{array}$ & $\begin{array}{c}\text { Madre / tía } \\
\text { materna }\end{array}$ & $\begin{array}{c}\text { Tío } \\
\text { materno }\end{array}$ \\
\hline Marubo & Otxi & Txitxo & Pano & Txai & Epa & Natxi & Ewa & Koka \\
Kashinawa & Huchi & Ichu & Xanu & Chai & Epa & Achi & Ewa & Kuka \\
Shipibo & Jochi & Chiko & Bambiki & Chai & Upa & Achi & Uwa & Koka \\
\hline
\end{tabular}


rentes etnias; pueden ser hereditarias o no, exogámicas o no. Como es el caso de las categorías de parentesco, muchos nombres de grupos sociales son compartidos entre diferentes etnias pano. Fleck (s.f.) ha notado, por ejemplo, que la denominación «inonawabo» ('gente del jaguar') o uno de sus cognados existe en diez etnias pano contemporáneas o históricas, y la denominación «barinawabo» ('gente del sol') en cuatro. La existencia de identidades compartidas, a pesar de sus significados sociales diferentes, facilita el reconocimiento del parentesco interétnico. Por ejemplo, si los inonawavo son mis kokavo (Figura 1) y me encuentro con un inonawavo de otra etnia, puedo llamarle koka, incorporándole así a mi grupo de parientes. Cuando los marubo se encuentran con gente pano en el estado de Acre, les preguntan ¿mi awe nawavo ra? ('¿a qué grupo social pertenece?’) y, dependiendo de la respuesta, aplican el término de parentesco correspondiente. El simple hecho de pertenecer a un grupo nawavo, aunque no sea uno de los dieciocho que existen entre los marubo, es suficiente para aplicar el término txai, que abarca el significado de 'primo cruzado' y 'amigo interétnico.'

A pesar de pertenecer a 18 diferentes grupos nawavo, todos los marubo pueden referirse a todos los otros por un término de parentesco, y por tanto todos los marubo se consideran parientes. Desde el momento en que se aplica un término de parentesco a un miembro de otro grupo nawavo, todos los miembros de aquel grupo se convierten en parientes de todos los miembros del que aplica el término. En la práctica, por supuesto, no se incorporaría a otro grupo social sin muchas discusiones entre líderes $\mathrm{y}$ viejos, y no consta que los marubo lo hayan hecho desde comienzos de siglo XX. Sin embargo, es evidente que sí lo hicieron entonces y que la alianza interétnica se convirtió por este método en fusión étnica. El hecho de compartir categorías y términos de parentesco e identidades homófonas facilitó esta fusión negociada de etnias. La alianza interétnica se consolidó cuando todos los miembros se colocaron dentro de un único universo de parentesco.

El nuevo sistema de parentesco halló su expresión en aspectos de los performances rituales de João Tuxaua y su círculo, entre ellos los del mito de orígenes. Hoy día este mito, Wenía, apenas se canta en fragmentos. Dicen los cantores que no pueden cantarlo porque es muy largo, que João Tuxáua lo cantaba durante al menos seis días. Wenía, entonces, no es sólo un discurso, sino que tiene que ser un performance. Eso implica no solamente cantar, sino que haya una fiesta, con mucha comida, que dure una semana, y que el cantor esté unas doce horas por día cantando y alentando a los jóvenes a que le sigan y canten con él. Implica, como se verá más tarde, todo el marco social de la fiesta marubo: colaboración entre malocas, suspensión del trabajo corriente, intercambios de comida, discursos ceremoniales, vestidos elaborados, danzas, cantos, sesiones de tambor y, gracias a la colaboración en la fiesta, muchas barrigas llenas de comida riquísima. Desde la muerte de João Tuxaua, que yo sepa, nadie ha hecho un performance completo de Wenía.

El canto de Wenía explica los orígenes de todos los grupos nawavo del universo social marubo, colocándoles a todos en una única narración (Melatti 1986). Después del origen individual de cada grupo, Wenía cuenta el viaje conjunto de los grupos, durante el cual aprenden sus nombres, las técnicas de la agricultura y otros conocimientos culturales. Reconocerse a uno mismo y sus orígenes en este canto resulta una 
de las claves de la identidad étnica marubo, pues a pesar de sus orígenes diversos, Wenía plantea que todos los grupos marubo viajaron juntos y obtuvieron los mismos conocimientos culturales, conocimientos que les hacen similares entre ellos, distinguiéndolos de otras etnias que no sean marubo.

Queda claro que el canto de Wenía en su versión contemporánea no es idéntico a cualquier versión que existía antes de la alianza interétnica. Representa décadas de creatividad ritual por parte de João Tuxaua, inspirada por sus visiones del mundo de los espíritus, donde éstos, según su hijo José, le explicaban los orígenes de todas las cosas, incluyendo los grupos nawavo. La versión así creada era adaptada a su contexto social, incorporando los orígenes de todos los miembros de la alianza. Esto nos indica también que el sistema de parentesco marubo es una creación consciente de actores sociales históricamente situados, no un sistema que simplemente se heredó de las generaciones previas. El círculo de João Tuxaua tuvo la oportunidad de discutir y negociar el parentesco y proponer una serie de prácticas más cercanas a lo que consideraban ideal. Como el canto Wenía que lo apoya, el sistema de parentesco marubo es parte tradición y parte creación específica en el contexto histórico.

Otro género de discurso que apoya al sistema de parentesco como sistema de acción social es el de ese vana. Ese quiere decir 'sabiduría' y se refiere a los conocimientos marubo sobre el comportamiento social correcto. Este comportamiento es el tema de frecuentes monólogos llamados ese vana, 'palabras de sabiduría'. Son reconocibles tanto por su tema-casi siempre el comportamiento social correcto-, por un ritmo y entonación particulares y por su larga duración, 45 minutos o más. Es una expresión clara del razonamiento sobre lo que se debe hacer y por qué conviene hacerlo: una filosofía de ética social.

La generación de João Tuxaua estableció una serie de alianzas matrimoniales entre grupos nawavo (Figura 2), muchas de ellas nuevas alianzas siguiendo los ideales propuestos por los líderes. Consideraban como ideal el matrimonio entre primos cruzados, repetido por múltiples generaciones, diciendo que era la mejor manera de asegurar que todo el mundo tuviera con quién casarse. Los líderes de la turma decían que si se establecían alianzas entre grupos nawavo, con intercambios de matrimonio entre primos cruzados, en la próxima generación todo el mundo sabría de dónde le vendría su esposo o esposa: de entre los hijos de sus tíos maternos. Por lo tanto, no habría falta de mujeres para hombres ni viceversa, habría muchos niños y la población crecería.

Las alianzas matrimoniales propuestas por el círculo de João Tuxaua requieren esfuerzo consciente de parte de los líderes que las apoyan. Aunque lo ideal sea casarse con un primo cruzado dentro de una alianza establecida entre grupos nawavo, cualquier marubo se puede casar con miembros de seis o siete grupos nawavo, pudiendo también casarse con alguien no marubo. Los líderes que apoyan las alianzas multigeneracionales buscan que estos matrimonios azarosos se reduzcan al mínimo y tratan de convencer a sus hijos y sobrinos que no se casen fuera de la alianza. Conseguir que todo el mundo se case de acuerdo con el ideal exige muchos discursos sobre la ética (ese vana), arengas tsaĩki y negociaciones. Los viejos alaban ejemplos exitosos, como el mostrado en la Figura 2. Los líderes que organizan y negocian estas alianzas pueden apuntar a su éxito demográfico como apoyo de sus argumentos a favor de la repetición de matrimonios entre primos cruzados. 


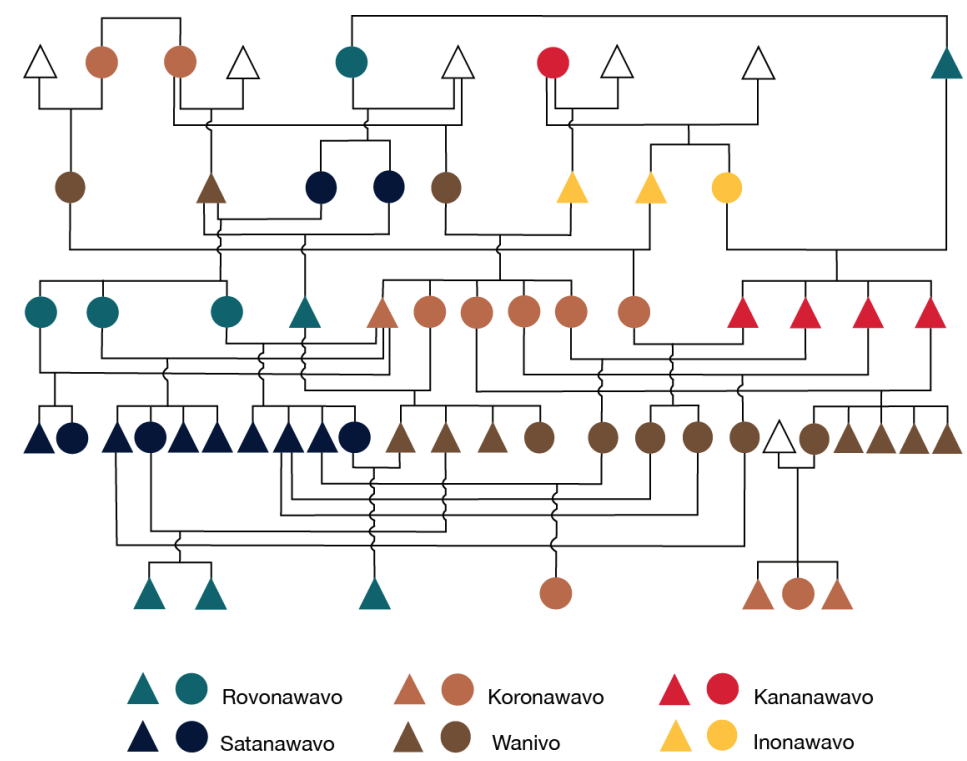

Figura 2: Cuatro generaciones de intercambios matrimoniales marubo. La segunda generación es la del círculo de João Tuxaua. La tercera generación es la nacida durante el periodo de aislamiento tras la fiebre del caucho. La penúltima generación eran jóvenes parejas recién casadas a finales del siglo XX. (Ilustración basada en datos genealógicos recopilados por Julio Cezar Melatti en 1975 y por Javier Ruedas en 1997-1998).

El sistema de acción social diseñado por la turma de João Tuxaua ha resultado en el crecimiento demográfico equilibrado de los grupos miembros de la alianza interétnica. Durante la generación entre 1975 y 1998, por ejemplo, la población marubo se dobló (Figura 3), pero aún con todo ese crecimiento, ningún linaje aumentó su población de manera desproporcionada (Ruedas 2001: 750); las proporciones de los linajes se mantuvieron estadísticamente inalteradas. Casi todos los grupos nawavo que vinieron a las cabeceras del Maronal y siguieron los propósitos de la turma han sobrevivido y crecido hasta el día de hoy (la única excepción es el linaje InonawavoKananawavo, en el cual ninguna de las mujeres que sobrevivieron a la fiebre del caucho tuvo hijas, lo cual en el sistema matrilineal marubo conlleva extinción del linaje). Hoy existen ocho linajes reproduciéndose activamente, compuestos por dieciséis grupos nawavo y con más de 1.600 personas habiendo empezado con apenas 50 . La propuesta de la turma -que seguir al sistema resultaría en crecimiento demográfico y en la supervivencia de los grupos nawavo- ha sido confirmada.

Los miembros del círculo pensaron profundamente en la ética, iniciaron un sistema de acción social, imaginaron y pusieron en marcha intercambios entre identidades. Justificaron sus propuestas con una filosofía considerada a fondo y expresada en discursos ceremoniales. Es en este contexto que podemos entender la creación del sistema ceremonial marubo. 


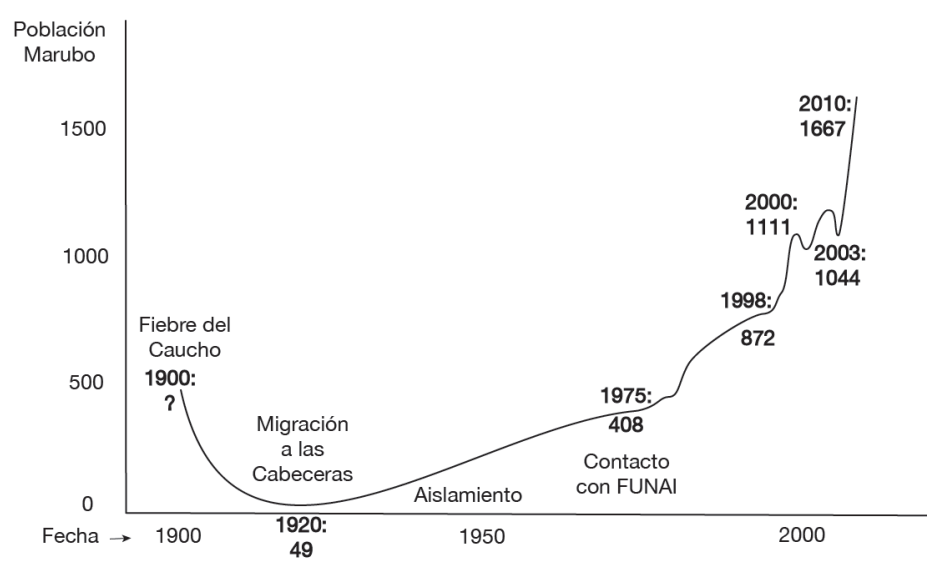

Figura 3: Curva demográfica marubo, con algunos eventos históricos de los siglos XX y XXI (Melatti s.f.; Ruedas 2001; Coutinho 2008; CTI/ISA 2011).

\section{Los ritos de curación}

Los ritos de curación tienen una posición privilegiada en la vida social e identidad étnica marubo. Han sido descritos a fondo por Montagner (1985) y Cesarino (2008). En esta sección, los pondré en contexto histórico y explicaré su importancia en las propuestas sociales de João Tuxaua y su círculo.

En la filosofía social del círculo de João Tuxaua, es de importancia central el cuidar de la salud de los otros y hacer todo lo posible para curarlos cuando sea necesario. Los ritos de curación se sitúan así en el contexto de la fiebre del caucho y de la reacción del círculo a aquella fiebre. Un punto fundamental que les definió fue el rechazo de las relaciones violentas y su reemplazo por los intercambios y las alianzas. Los «bravos», dicen, se mataban entre ellos y, en consecuencia, todos pasaban hambre y los niños no crecían bien. En cambio ellos, es decir los que escogieron ir con el círculo, cuidaban unos de otros y especialmente de su salud. João Tuxaua curaba a todo el mundo, con shõki, ritos chamánicos o plantas medicinales. Los ritos de curación ejemplificaban su filosofía de supervivencia y buena vida, siendo en parte una teoría de cómo sobrevivir a la fiebre del caucho. Hoy día son todavía un aspecto fundamental de la identidad étnica marubo. Tanto los marubo como las otras etnias del Yavarí los consideran como un rasgo característico de la cultura marubo.

Los ritos de curación, especialmente los shõkia, pueden ser contextos para discusiones políticas (Ruedas 2002). Dependiendo de la seriedad de la enfermedad, a un shõkia pueden asistir varios cantores kẽchĩtxo o, en los casos más críticos, casi todos los kẽchĩtxo del poblado. Como los kẽchĩtxo son, a menudo, también las máximas autoridades políticas, si algún tema requiere discusión entre ellos, se puede hablar en un shõkia. Sin embargo, el objetivo principal de un rito de curación siempre es curar. Los cantores típicamente cantan toda la noche, y siempre que las observé, las discusiones políticas en un shõkia tenían lugar al principio del rito y ocupaban sólo una pequeña 
Cuadro 2: Algunos componentes del sistema ceremonial marubo

\begin{tabular}{l} 
Géneros de discurso \\
\hline Ese vana \\
Discursos sobre ética social. Dirigidos por \\
adultos, frecuentemente por dueños de ma- \\
loca o líderes visitantes, a los habitantes \\
de una maloca. Informan sobre comporta- \\
mientos equivocados y cuáles son los com- \\
portamientos sociales correctos. \\
Tsaĩki
\end{tabular}

Discursos y arengas ceremoniales. Intercambia-dos por líderes de pueblos diferentes durante fiestas, o dirigidos por viejos a una maloca para alentar al comportamiento esperado.

\section{Saiti}

Mitos cantados en verso. Normalmente cantados durante fiestas, con participación de jovenes de todo el pueblo.

\section{Shõki}

Cantos de cura. Cantados por los cantores kêchĩtxo durante los ritos shõkia para limpiar el cuerpo del paciente del patógeno sospechado.

\section{Iniki}

Cantos chamánicos, cantados mientras que un chamán está entrando o ha entrado en trance.

\section{Pajelança}

No tiene nombre marubo. Sesión chamánica en la cual un especialista llamado romeya canta iniki y entra en trance, comunicando de diversas formas con los espíritus yove y curando enfermedades y dolores.

\section{Eventos comunicativos}

\section{Reuniones}

Reuniones para hablar de temas políticos. Pueden participar jóvenes además de viejos y líderes.

\section{Radiocomunicaciones}

Comunicaciones entre poblados, o entre poblados y ciudades, a través del sistema de radios.

\section{Fiestas}

\section{Akoya}

Fiesta del tambor de madera ako. Incorpora al poblado entero en la construcción y transporte del tambor, en la procura de comida, en danzas y en la repetición de cantos saiti.

\section{Tanamea o Wakaya}

Fiesta incorporando a varios poblados. Incluye convites ceremoniales, intercambio de discursos tsai iki, consumición de huevos de tortuga y cerveza de maíz, cantos saiti, y una invasión ceremonial del pueblo anfitrión.

\section{Shavá Sai Aká}

Fiesta para restablecer un equilibrio entre las fuerzas y entidades que componen el mundo desde la perspectiva marubo.

$$
\text { Ritos de cura }
$$

\section{Shõkia}

Rito de cura por cantos.

parte de éste. Como se discutirá en breve, los organizadores del movimiento indígena llegarían a encontrar limitaciones en el shõkia como sitio para la acción política, e introdujeron un nuevo tipo de evento comunicativo (speech event, Hymes 1974), la reunión. Pero el shõkia sigue cumpliendo muy efectivamente uno de los papeles otorgados por el círculo de João Tuxaua al ser incorporado al sistema ceremonial: un sitio donde la familia y la comunidad se juntan para cuidar de los enfermos y expresar su solidaridad (oniska). En este sentido sigue ejemplificando ritualmente la filosofía de supervivencia de la fiebre del caucho: como respuesta a la violencia, el cuidado mutuo; como respuesta al etnocidio, ritos de curación para que sobrevivan los parientes. 


\section{Las fiestas}

Como los ritos de curación, las fiestas ejemplifican la filosofía de intercambio, buena vida, buena salud y barrigas llenas, por la que abogaron João Tuxaua y su círculo. Las fiestas implican, como se propone más adelante, toda una serie de intercambios entre grupos, sean malocas dentro de un pueblo o diferentes poblados marubo. Múltiples malocas contribuyen con comida y mano de obra, colaboran en la caza, participan en las danzas y los cantos. Durante un tanamea también ocurre un intercambio de presentes y de discursos ceremoniales tsaĩki entre representantes de los huéspedes y anfitriones. Durante esos discursos se hace explícita la filosofía de la fiesta en el contexto de la historia marubo. Un consultor me resumió el contenido de sus discursos de la siguiente manera:

«Antiguamente, todo el mundo se peleaba, se engañaba, y discutían. Esto era malo, porque todo el mundo estaba triste, con hambre, muriendo o muertos. Entonces [apuntando hacia arriba] dios nos envió palabras. Cuando recibimos las palabras, dejamos de pelearnos, en vez de pelear cazábamos y criábamos las chacras, comíamos y hacíamos fiestas. Una barriga llena da fuerza para trabajar. Eso es lo que dice el tsaikii».

La fiesta se propone como aspecto fundamental del modo de acción social que diferencia a los marubo de aquellos otros (los «bravos») que no se sumaron al proyecto, modo a través del cual sobrevivieron física y culturalmente a la fiebre del caucho, siendo todavía parte fundamental de la identidad étnica marubo. La fiesta, por tanto, pone en acción la ética de antiviolencia, supervivencia e intercambio que desarrolló el círculo de João Tuxaua como antídoto a la fiebre del caucho.

\section{Las reuniones}

A finales de siglo XX, algunos marubo reaccionaron ante otra integración forzada al sistema mundial creando nuevas ceremonias que les darían más poder de acción ante nuevas y diferentes amenazas. El contexto histórico para el desarrollo de las reuniones del movimiento indígena fue la incorporación a la burocracia nacional brasileña. La Fundação Nacional do Índio (FUNAI) estableció «polos de atracción» en los ríos Curuçá e Ituí en los años 70, llevando a muchos marubo a migrar a estos lugares, desde las cabeceras a los cursos principales de estos ríos. La migración terminaría con el abandono total de las cabeceras en favor de los ríos principales y la intensificación de las relaciones comerciales, laborales, burocráticas y médicas con los nawa. Desde la perspectiva de los organizadores del movimiento, los marubo se enfrentaban a nuevas formas de explotación, exclusión y dominación que podrían extinguirlos tan certeramente como las escopetas de los caucheros. Así, una de sus armas principales ante esta situación histórica fueron las reuniones, desde donde forjaron una nueva alianza interétnica que transformó las relaciones entre indígenas y no-indígenas en el Yavarí.

Uno de los fundadores del movimiento indígena en el Yavarí fue Clovis Rufino Reis. El 21 y 22 de julio de 1997 me contó su historia mientras subíamos el Yavarí en el pequeño barco que entonces tenía la organización indígena del Yavarí, CIVAJA. Clovis nació en 1966, cuando su familia vivía todavía en las cabeceras de los ríos 
pequeños. Su madre se casó con un maderero tikuna que vivía en la ciudad de Benjamin Constant y fue ahí donde él se crío, bilingüe y entre culturas. Mientras tanto, la FUNAI entró en el Yavarí y estableció un puesto en el Curuçá, a donde se mudó su familia. Clovis empezó a visitar a su familia ahí, mostrándose muy crítico con la política seguida por la FUNAI. Clovis me explicó que desde su perspectiva la FUNAI actuaba con paternalismo; querían ser el gran padre, me dijo, y cuidar de los indios como hijos. Pero en realidad les explotarían, sacando partida de los recursos naturales del Yavarí y negándoles a los indios la independencia y su propia tierra. Clovis y sus compañeros trabajaron para invertir las relaciones de poder entre indígenas y FUNAI y crear mecanismos para influir en la política del estado brasileño hacia ellos:

«En 1981, volví al área [indígena] y fue entonces que me casé con mi primera mujer. Me quedé hasta 1983 en São Sebastião [localización del puesto de la FUNAI en el Curuçá]. Empecé a organizar reuniones en el área con los líderes marubo para discutir de asuntos, para mostrarles la realidad de la situación y lo que verdaderamente estaba pasando. Estas fueron las primeras reuniones no tradicionales. Antes de eso, los asuntos se hablaban solamente cuando los viejos ya estaban reunidos en los bancos paralelos para tomar rapé después de cenar. Yo fui el primero en organizar reuniones sólo para hablar de lo que estaba pasando. Durante este tiempo, a partir de 1977, también era el intérprete para los líderes marubo en algunas reuniones, intercambiando ideas, haciendo propuestas, y después yo fui el que organizaba reuniones para poner las ideas en movimiento. En 1983 y 1984, fui la primera persona [marubo] en hacer contacto con los mayoruna [matses] para hablar de asuntos comunes a todos los indígenas del Yavarí. También en 1983 me conecté con COIAB [Coordenação das Organizações Indígenas da Amazônia Brasileira] y empecé a decir que los indios, y especialmente los marubo, iban a hacer sus propias decisiones sobre el futuro y no dejar que los blancos decidieran para nosotros».

En otra narración, Clovis menciona un evento clave para el movimiento indígena: el momento en que João Tuxaua decidió apoyar la formación de una organización indígena multiétnica en el Yavarí:

«CIVAJA no existiría si no fuera por João Tuxaua. Cuando empezamos a subir el Curuçá para organizar a la gente, pensaban que Darcy y yo sólo éramos niños causando problemas. Los líderes no nos escuchaban. Entonces, João Tuxaua dijo que la gente debía escucharnos, que lo que proponíamos era el camino correcto. Desde ese momento, CIVAJA empezó a tener apoyo en el Curuçá. [...] Muchas veces, cuando hablo a la gente, me inspiro con las buenas palabras. Luego, cuando he acabado, no puedo ni acordarme de lo que dije ni entender cómo lo dije. Esa inspiración es de João Tuxaua».

José Barbosa, hijo de João Tuxaua, me clarificó el mecanismo de la inspiración verbal:

«Ese no era el espíritu de mi padre que ayudó a Clovis, fueron los espíritus yove llamados por mi padre. Cuando Clovis empezó a hablar, a nadie le gustaba. FUNAI le odiaba, había gente que quería matarlo. Entonces mi padre fue y obtuvo miel, cantó hacia ella y se la dio a Clovis a comer. Por eso los yove ayudan a Clovis. Mi padre llamó Mawa a entrar en la miel. Mawa ayuda a la gente a hablar».

Volvemos a la primera narración de Clovis para ver cómo las reuniones condujeron a una alianza interétnica: 
«En 1990, en Maronal [poblado entonces en el río Curuçá, donde vivió João Tuxaua hasta su muerte en 1996], tuvimos una reunión para planear la reunión de todos los pueblos indígenas del Yavarí en Atalaia do Norte. En 1991 invité a todos los indios del Yavarí al Primer Encuentro de los Indios del Yavarí. Antes había estado en São Raimundo [poblado matses] y entre los kanamari, pasando una semana en cada lugar, diciendo que estábamos siendo engañados, explotados. Después del Primer Encuentro se creó la Comisión Indígena del Valle del Yavarí, con Darcy de coordinador, yo de vice, y representantes mayoruna y kanamari. Esto duró hasta junio de 1992, cuando tuvimos la Primera Asamblea de los Pueblos Indígenas del Valle del Yavarí. Tuvo participación de la Pastoral Indigenista, COIAB, CIMI, Fundação Nacional de Saúde y FUNAI, además de los líderes indígenas. [La Asamblea creó CIVAJA, el Conselho Indígena do Vale do Javari.] Darcy fue electo otra vez coordinador general y yo vicecoordinador. Cabral fue el representante kanamari, y Joaquim Mayoruna de Lobo y Antonio Mayoruna de Lameirão. También fui a Manaus a asumir la posición de coordinador regional con COIAB».

En las narraciones de Clovis vemos el proceso de creación de la nueva alianza interétnica, incorporando en primer lugar marubo, matses y kanamari y, luego, también matis y kulina. El mecanismo principal fueron las reuniones, que, como explica Clovis y confirman otras fuentes, era un nuevo género de evento comunicativo. En parte, era la forma de organizar propia del movimiento indígena nacional e internacional, que Clovis y su compañero Darcy Comapa habían aprendido de sus contactos con otros activistas indígenas en Manaus y de las organizaciones de apoyo como CIMI y la Campanha Javari. Sin embargo, en su forma específicamente marubo, la reunión guarda una estrecha conexión con los shõkia.

Para Clovis, las reuniones eran en parte una manera de resolver su frustración con el shõkia como mecanismo de acción política. Los curadores, dice, sólo hablaban de temas tradicionales y era muy difícil que se discutieran temas de política contemporánea y de relaciones con la burocracia brasileña. Si acaso se discutían, era sólo hasta empezar los cantos. En cambio, en una reunión se abordan directamente los temas políticos que son el objetivo central del evento. Pero al mismo tiempo, las reuniones carecen de legitimidad sin la participación de las mismas autoridades políticas que asistían a los shõkia. Las reuniones, de cierto modo, transfieren la función política del shõki a otro contexto. Ahí siguen los hombres mayores, en su mayoría kẽchĩtxo, tomando rapé (pero no ayahuasca) para hablar mejor y expresando sus opiniones en discursos formalizados. Las reuniones tuvieron éxito precisamente por su continuidad con los shóki y no tanto por su novedad. Es en este sentido que se pueden considerar las reuniones -al menos las reuniones entre marubo en los pueblos, si no las reuniones multiétnicas en las ciudades-como parte del sistema ceremonial marubo.

La gran novedad, como mencionaron Clovis y otros, es que en una reunión las ideas las pueden proponer jóvenes marubo bilingües para que las discutan los viejos -lo que Clovis llama «mostrar la realidad de la situación» y «poner ideas en movimiento»-. En la práctica, los jóvenes proponen ideas para discutir, los viejos las discuten y llegan a una opinión o decisión y los jóvenes se encargan de poner en práctica la decisión. En ausencia de los viejos, la reunión no tiene legitimidad. Por eso, la decisión de João Tuxaua de apoyar el proceso de organización indígena multiétnico 
fue determinante. Siendo el más influyente líder marubo, su palabra llevaba peso y, como dijo Clovis, a partir de ese momento comenzaron a escucharle.

Las reuniones no sólo conectaban a los líderes tradicionales con los nuevos activistas del movimiento indígena, sino que también los jóvenes servían de enlace con el mundo fuera de los poblados marubo. La decisión de una reunión que incluía a los kẽchĩtxo representaba la opinión formal de los pueblos participantes y, por tanto, cuando un representante del movimiento repetía esa opinión, no estaba hablando ya por sí mismo, sino en nombre de todos los pueblos que habían participado en la reunión. Las reuniones transformaban a los organizadores de activistas individuales en representantes de etnias enteras, y daban así peso a sus palabras. Al mismo tiempo, las reuniones daban a las autoridades tradicionales una manera de proyectar su poder al exterior.

El resultado de las reuniones de finales de los años 80 y comienzos de los 90, como vimos en la narración de Clovis, fue el establecimiento de una alianza entre marubo, matses y kanamari para presionar al gobierno brasileño y reaccionar rápidamente ante la sociedad nacional envolvente. La organización indígena, CIVAJA, resultó ser un instrumento efectivo para los pueblos indígenas del Yavarí a la hora de presionar a la FUNAI para cambiar sus políticas. Poco a poco, el sueño de ver lograda la inversión de las relaciones de poder empezó a realizarse. Pero faltaba un elemento clave para articular las reuniones de los indígenas en los pueblos con la nueva organización en la ciudad de Atalaia: las radios.

\section{Las radios}

Uno de los primeros proyectos de CIVAJA fue la instalación de un sistema de comunicaciones por radio para los pueblos indígenas del Yavarí. Un viaje entre Maronal y Atalaia do Norte suele durar entre 12 y 14 días. Con las reuniones y la organización, el movimiento indígena había conseguido crear una vía de comunicación entre los pueblos indígenas y los representantes de la burocracia brasileña. Pero aquella comunicación podía tardar meses en ir y venir desde y hacia los pueblos más lejanos. Las radios hicieron posible la comunicación instantánea entre Atalaia y los pueblos del interior. Esto dio más poder a los pueblos indígenas ante la burocracia brasileña, pues ahora podían ser consultados y divulgar decisiones y opiniones rápidamente. $\mathrm{Al}$ mismo tiempo, se creó un nuevo tipo de evento comunicativo entre los marubo. La comunicación por radio desarrolló sus propias reglas y costumbres, se colocó de intermediaria entre las reuniones en los pueblos y las reuniones de CIVAJA en Atalaia, y se convirtió en tema para eventos metadiscursivos: he escuchado discursos ese vana de casi una hora de duración sobre el tema de cómo deberían ser las conversaciones por radio.

En las ocasiones que pude observar, cuando se había tomado una decisión importante en una reunión, a menudo se tomaba el tiempo para «pasar un radiograma». El radiograma es un documento que expresa formalmente una opinión, decisión, o petición comunicada por la radio. Cuando en una reunión se tomaba una decisión importante, un bilingüe se hacía cargo de expresar la decisión en portugués escrito. 
Durante el horario de la radio, se solicitaba la presencia de un escribano en las oficinas de CIVAJA en Atalaia. La decisión se leía lentamente y el escribano la transcribía en Atalaia, palabra por palabra. Al final se añadía una fórmula explicando el ámbito político de la decisión, como «nosotros líderes de Maronal»o «Yo Alfredo, cacique de Maronal», seguida de los nombres de las autoridades presentes en la reunión o que hubieran expresado su apoyo a ella. Los radiogramas se consideran legítimas expresiones de la voluntad colectiva de grupos indígenas en el Yavarí. Ofrecen una manera directa para que las autoridades indígenas presionen a la FUNAI u otras agencias gubernamentales.

\section{La acción ritual en la transformación de relaciones de poder}

En 1998, los marubo del Curuçá decidieron que el jefe del puesto de la FUNAI en aquel río debía ser indígena y que ellos decidirían quién ocuparía la posición. Antes de 1998, nunca un jefe de puesto de la FUNAI en el Yavarí había sido indígena y la idea de que los indígenas nombraran sus propios jefes de puesto sonaba a insurrección. En efecto, era un paso importante hacia la inversión de relaciones de poder entre indígenas y FUNAI. Los jefes de puesto son el contacto más inmediato con los pueblos del interior del Yavarí y están a cargo de fiscalizar la zona, protegerla de invasiones y aplicar los recursos de la FUNAI para asegurar la seguridad y el desarrollo de los pueblos indígenas. En 1998, los marubo estaban diciendo que ellos mismos deberían decidir cuál era la visión del futuro por desarrollar con los recursos.

Los marubo del Curuçá fueron los primeros en el Yavarí en conseguir un jefe de puesto indígena y el uso del sistema ceremonial fue una de las herramientas que usaron para conseguir ese objetivo. Para mostrar las conexiones entre el sistema ceremonial y la transformación de relaciones de poder en el Yavarí, seguiré los movimientos de un experto en acción ritual a través de 45 días que incluyeron un shõkia largo, un akoya, dos reuniones y dos radiogramas.

Estas ceremonias pueden distinguirse analíticamente en «tradicionales y modernas», pero en la práctica los individuos se mueven entre estas categorías de eventos y sus efectos se interrelacionan de maneras imprevisibles. El sistema ceremonial se desarrolló como forma de resistencia ante la amenaza del sistema mundial. Los ritos de curación, por ejemplo, no son simplemente la expresión del deseo de curar. Tienen una intensidad tremenda, los cantores privándose de sueño y cantando toda la noche, tomando grandes cantidades de rapé y a menudo parando el trabajo cotidiano. La intensidad de los ritos de curación marubo refleja en parte el afán por cuidar de la supervivencia de todos los individuos, lo que viene de la experiencia histórica de la fiebre del caucho. La ideología de las fiestas también está basada en ideas de cómo sobrevivir a la fiebre del caucho: fiestas, intercambios y barrigas llenas como respuestas a la violencia del sistema mundial. Las reuniones son explícitamente una forma de aplicar la influencia indígena al funcionamiento de la burocracia nacional. El radiograma comunica directamente las decisiones indígenas a los órganos de la burocracia. Todos estos objetivos y sus formas ceremoniales correspondientes siguen muy vigentes. Este ejemplo mostrará que tanto las formas «tradicionales» $\mathrm{y}$ «sagra- 
das» como las «modernas» y «seculares» conforman un conjunto, con las mismas personas en la organización y la participación y con los eventos de un ámbito influyendo en el éxito del otro.

Era el final de la estación de lluvias en 1998, la época del año que los marubo consideran la mejor para cazar, ya que, dicen, los animales están más gordos que nunca. En la maloca de mi anfitrión, José Barbosa, hubo cacerías exitosas, buenas cosechas y delicias gastronómicas. Entre el 15 de abril y el 29 de mayo participaron en once cacerías en las que se mataron 116 monos, 15 pecaríes, 2 ciervos, 2 jabalíes y un tapir, cosecharon maíz e hicieron chicha y tostaron farinha de mandioca. Muy de acuerdo con los ideales del círculo de João Tuxaua, las barrigas estaban llenas, las invitaciones a comer entre malocas se sucedían y la acción ritual era constante.

En la maloca de José, empezó un shõkia que casi no pararía hasta mediados de mayo. El 16 de abril, Pedro -hermano de José- cantó solo para aliviar los dolores de cuerpo de su esposa. Cantó solo durante tres noches; entonces llegó su cuñado y cantaron juntos. Al día siguiente se sumó José y eran tres cantores. Pero el día 22 llegó un mensaje por la radio de CIVAJA que causó la convocatoria de una reunión. El asunto que suscitaba dicha reunión había empezado en enero de ese mismo año.

A comienzos de enero, mientras yo volvía de una fiesta en el río Ituí, tuvieron lugar por la radio una serie de consultas sobre el tema de los jefes de puesto de la FUNAI. Un joven bilingüe me resumió: «Hemos estado discutiendo el tema de FUNAI. Ya no queremos jefes de puesto nawa, porque no nos explican la realidad de las cosas, ni intercambian ideas con los líderes. Queremos jefes de puesto indígenas». José me dijo que su hijo Manoel podría convertirse en jefe de puesto de la FUNAI. El jefe previo, Luis, se había jubilado, dijo, y un empleado marubo de la FUNAI les había pedido que tuvieran una reunión en Maronal para ver qué jefe de puesto querían. Habían decidido que querían jefes de puesto marubo y específicamente a Manoel, que era entonces el secretario de CIVAJA, había estudiado en la ciudad y era cómodamente bilingüe.

En la mañana del 22 de abril, Manoel pidió desde Atalaia que su padre viniera a hablar en la radio. Le dijo a José que se había aceptado su nombramiento, pero el decreto oficial nombrándole como jefe de puesto había sido atrasado porque en la FUNAI pensaban que los líderes de Maronal no lo apoyaban unánimemente. Según Manoel, el jefe interino de la FUNAI en Atalaia, Gilmar, estaba decepcionado con los indígenas porque en enero todos habían pedido jefes de puesto indígenas, pero luego habían cambiado de opiniones. Ahora, los matses, kanamari y matis habían pedido que volvieran sus jefes de puesto no-indígenas, y Gilmar escuchaba rumores de que en el Curuçá querían que regresara Luis. Por eso, Gilmar estaba atrasando el nombramiento. Manoel pedía que se reunieran para hablar del asunto.

Esa noche, José fue a la maloca de su hermano Alfredo, cacique de Maronal. Ahí se habían reunido cuatro dueños de maloca, tres hermanos de dueños de maloca y un yerno de dueño de maloca. Hablaron del tema y todos confirmaron su apoyo a Manoel. Al día siguiente, José mandó escribir una carta resumiendo los resultados de la reunión, para enviarla en una canoa que iba a bajar el Curuçá. Mandó también que se firmara con los nombres de todos los que habían asistido a la reunión, además de otros dos dueños de maloca con quien había hablado. Pero no era suficiente. Al día 
siguiente, Alfredo avisó que quería enviar un radiograma ese mismo día, para que no hubiera ninguna duda sobre su posición. Alfredo mandó a una joven bilingüe escribir el radiograma, firmando esta vez "Alfredo Barbosa, cacique general de la nación marubo», exigiendo el nombramiento de Manoel sin demora, y afirmando «No queremos que se repita otra vez este problema».

Con el problema del jefe de puesto resuelto de momento, José y Pedro recomenzaron su shõkia. La noche del 26 cantaron por la salud de una hija de José; desde entonces hasta el 17 de mayo, sólo descansarían tres noches. Al principio sólo participaban los dos hermanos y su cuñado Alberto, pero poco a poco fueron llegando otros kẽchĩtxo. Ayudó la abundancia de comida que había en la maloca esas semanas, pues siempre que había carne fresca, José enviaba a sus hijos a convidar a otras malocas a comer y los hombres mayores se quedaban después de la cena para cantar o conversar y escuchar los cantos. Un dueño de maloca empezó a sufrir dolores en el hombro y vino a pedir que cantaran por él. En las primeras dos semanas de mayo, solían estar presentes de noche en la maloca de José al menos cuatro dueños de maloca y otros tres hermanos de dueños, y a veces había hasta siete dueños de maloca presentes en el shõkia. José aprovechó la oportunidad de preparar su cosecha de maíz. Necesitaba limpiar su chacra antes de cosechar y, dado que los monos y el jabalí que llegaron el día 12 le permitían ofrecer buenos almuerzos a sus convidados, pidió a algunos de los hombres que asistían de noche al rito de curación que le ayudaran con la tarea, lo cual hicieron los días 13 y 14 de mayo.

El 14 de mayo, mientras los cantores tomaban rapé y charlaban en los bancos paralelos (Montagner y Melatti 1986), Pedro estaba hablando de sus encuentros con otra gente pano en las ciudades del estado de Acre. Cuando encuentras otro indio ahí, dijo, le preguntas «¿mi awe nawavo ra?» ('¿de qué nawavo eres?’). Casi todos tenían un nawavo como tenían los marubo, dijo; había conocido Satanawavo, Awanawavo, Yawanawavo, Kashinawa, Poyanawa, Yaminawa, y Sharanawa. Cada vez que conversaba con uno, le preguntaba si tenían malocas, si tenían muka (medicinas botánicas) o shõki, si tenían saiti (los mitos cantados), cuáles comidas consideraban buenas y cómo comían.

El 17 de mayo acabó el shõkia, pues José había decidido emprender otro proyecto ceremonial: iba a organizar una fiesta akoya. Me lo dijo por la mañana del día 16, antes de salir a cosechar el maíz. Esa tarde fue a ver a un hijo de Alfredo. Éste había ido a Cruzeiro do Sul y su hijo estaba dirigiendo el trabajo de la maloca en su ausencia. José le pidió que le prestara mano de obra para ayudarle a cosechar bananas para la fiesta. El hijo de Alfredo consintió.

De vuelta a la maloca de José, cenamos y fueron llegando los participantes en el shõkia de esa noche (la del 16). Además de José y Pedro, estaban todavía Alberto y otros dos hombres importantes. La maloca estaba llena de huéspedes por el shõkia: una mujer y varios hijos de Alberto se estaban quedando ahí y un sobrino de Alberto con su familia había llegado para que les cantaran los kẽchĩtxo. Esa noche había cinco cantores y otro dueño de maloca presentes. Mientras tomaban rapé, José explicó su decisión de organizar el akoya:

«Quiero tener el akoya ahora mismo. Muchos dicen que sería mejor esperar. Dicen que hay muchos hombres mayores viajando. Pero la fiesta es para que los jóvenes vean 
cómo es un verdadero akoya. Hay muchos jóvenes y niños aquí, y muchas mujeres. La fiesta la organizan los viejos para los jóvenes, y como hay muchos jóvenes, deberíamos tener la fiesta. Otros dicen que hay una epidemia de malaria, pero la epidemia está pasando. Algunos dicen que hay poca comida. Hay muchas chacras recién plantadas, que todavía no dan bananas. Pero entre todos, si todo el mundo ayuda, no dando mucho pero sólo un poco, y si buscamos en las chacras abandonadas, todos juntos encontraremos las bananas. Es mejor tener el akoya ahora. No tengo ako y eso es malo. Los niños deben aprender la tradición del akoya para que no desaparezca. Y quiero tener el akoya mientras sigue aquí el antropólogo».

José consiguió apoyo para su akoya. Al día siguiente, llegaron cinco jóvenes de la maloca de Alfredo para ayudarle a traer bananas, y al otro día José organizó el vina atxia, ritual para dar fuerza a los cazadores. Participaron 9 de las 11 malocas de Maronal, alguien trajo un ciervo cazado y la maloca de José se abrió para dar de comer a todo el pueblo. Al amanecer el día 19, salieron los cazadores en busca de carne. Los siguientes días fueron más tranquilos. José amarró las fajas de elotes cosechados y organizó un grupo de seis personas de tres malocas para cortar leña.

En la noche del 22, volvieron los cazadores con 44 monos. Las mujeres empezaron a preparar la chicha. Estaban la mujer de Pedro y las dos de José, la de Alberto y la de su sobrino, que ya eran huéspedes por el shõkia, y llegaron otras cuatro mujeres a hacer hogueras en la maloca. José mandó otra vez a invitar al pueblo entero a comer. Al día siguiente era fiesta; vinieron de todas las malocas del pueblo a comer. José mandó derribar el árbol del ako. Para colmo de felicidad, alguien mató un tapir y se lo entregó a José para que se cocinara en su maloca y así se distribuyera al pueblo. No podía ser más completo el éxito.

Esa noche empezaron las danzas en la maloca de José, informales y jocosas para comenzar. José seguía vigilando la organización de la mano de obra para el éxito de la fiesta: el 24 organizó otro grupo, de tres malocas, para cortar más leña, pues las hogueras no podían parar. A pocos kilómetros del pueblo, Pedro supervisaba el corte del ako, que se acabó ese día. El ambiente de fiesta llenaba el pueblo, casi nadie hacía trabajo cotidiano y la maloca de José daba de comer a todo el que se presentara.

El 25 culminó la fiesta. El ako fue llevado hasta la maloca de José por 16 hombres jóvenes de 8 malocas. Cada poco paraban para tocar el tambor $y$, mientras lo tocaban, las mujeres del pueblo pasaban y cada una tocaba en las costillas a cualquier hombre que la llamara pano. Cuando llegaron a la maloca, izaron el ako, lo amarraron a dos postes al lado de los bancos paralelos y lo tocaron. Comimos monos, tapir y chicha, y comenzaron las danzas. En una danza, una cadena de jóvenes tomados de las manos circuló por la maloca, preguntando en canto, « ¿Mi awe nawavo ra?» y proponiendo respuestas como «¿Rovonawavo ra?». Finalmente, un especialista convidado cantó saiti toda la noche. Al amanecer, los invitados fueron festejados con los restos del tapir. El akoya se había acabado.

La maloca se vació de sus huéspedes. No había acción ritual y volvió la cotidianidad. Pero en la mañana del día 30, Clovis pidió por radio que se organizara una reunión en Maronal para discutir, otra vez, el tema del jefe de puesto. Después de comer, José envió a su hermano y a un hijo a las malocas más distantes para convidar a sus dueños a la reunión. 
La reunión tuvo lugar al anochecer. Una joven bilingüe introdujo el tema. Después de pedir jefes de puesto indígenas en enero, las otras etnias del Yavarí habían pedido la vuelta de sus jefes de puesto no-indígenas. El decreto nombrando a Manoel había llegado, dijo, pero se oía en Atalaia que algunos preferían que volviera Luis. Había que decidir. La discusión fue larga. Estaban presentes siete hombres influyentes, tomando rapé y haciendo discursos. Todos menos uno habían participado en el shõkia de José, y todos en su akoya. Pedro dijo que un jefe de puesto indígena sería onisi, o sea, alguien que comparte tristeza, tiene empatía o solidaridad. José enfatizó que los jefes de puesto no-indígenas traían nawã vana (palabras de extranjero) y no escuchaban yurã vana (palabras de indígenas). Pero los marubo tienen ese, dijo. Era mejor un jefe de puesto indígena porque escucharía a los viejos marubo y sus yurã vana. Todos los presentes concordaron en pedir, otra vez, a Manoel como jefe de puesto para el Curuçá.

Al día siguiente, enviaron otro radiograma, reiterando que querían a Manoel. Esta vez dio resultado. Aunque tardó unos meses, Manoel fue nombrado jefe de puesto para el Curuçá, puesto que ocupa hasta el presente. Por primera vez, los marubo habían podido determinar a quién se contrataba para vigilar su tierra.

\section{Conclusión}

La experiencia histórica de los marubo es un ejemplo del proceso descrito por Whitten (2003): en la Amazonía indígena, el discurso vehicula el poder, mediando en transiciones entre ordenamientos sociales y, especialmente, desconexiones del y reconexiones al sistema mundial. La desconexión ocurrió a principios del siglo XX, cuando los antepasados de los marubo, enfrentándose a la violencia de la fiebre del caucho, optaron por aislarse en las cabeceras de los riachuelos. Esta migración implicó un cambio radical de los ordenamientos sociales, ya que antes de eso los grupos nawavo estaban extendidos por casi toda la cuenca del Yavarí, mientras que después fueron un único grupo local con cinco malocas. Los géneros de discurso que integraron en un nuevo sistema ceremonial-saiti, shõki, iniki, tsaîki y ese vana- llevaban mensajes sobre qué tipo de relaciones sociales les permitirían sobrevivir y prosperar en esas difíciles circunstancias. La interpretación histórica de la fiebre del caucho se expresó en formato ritual: comer, tener barrigas llenas e intercambiar en las fiestas, cuidarse y curarse con los ritos de curación. Décadas después, la reconexión ocurrió cuando la FUNAI llegó al Yavarí. De nuevo, los discursos mediaron en una transición entre ordenamientos sociales, esta vez hacia uno en el cual los marubo se aliaron con las otras etnias del Yavarí para presionar a los órganos de la burocracia brasileña. Los discursos de las reuniones explícitamente impulsaron el poder indígena de tomar sus propias decisiones.

Al enfrentarse tanto a la fiebre del caucho como a la incorporación burocrática al estado, los marubo respondieron creando alianzas interétnicas. Éstas ofrecen una respuesta parcial a la paradoja presentada por Erikson (1993): que los pueblos pano se caracterizan por la atomización étnica, pero al mismo tiempo por una unidad cultural que cruza fronteras étnicas. En el caso marubo, vemos una multiplicación de identidades nawavo, pero también la creación de sistemas de relaciones entre ellas. 
La alianza interétnica es uno de esos sistemas. La experiencia marubo nos muestra cómo los símbolos compartidos, especialmente los símbolos míticos y las categorías de parentesco, pueden usarse para facilitar la alianza interétnica y, eventualmente, la fusión en una etnia. Aunque los símbolos y categorías tengan diferentes significados sociales en diferentes etnias, estas diferencias se pueden negociar hasta llegar a una interpretación compartida.

La recontextualización de discursos (Graham 1995; Oakdale 2009) es una de las claves del desarrollo de una nueva identidad étnica, la marubo. Aún en los años 1970, pocos marubo se consideraban como tales; más bien, la identidad principal seguía siendo la del grupo nawavo (Melatti 1977). Sin embargo, antes de finales del siglo $\mathrm{XX}$, los jóvenes ya suplían su identidad de nawavo con una identidad étnica marubo. Podemos ver una de las bases de esta nueva identidad en la recontextualización del mito Wenía, ya que João Tuxaua la ajustó para incluir a los grupos nawavo de la alianza interétnica en una única narración histórica, facilitando que se vieran como un pueblo con origen e historia comunes. De manera más general, podemos considerar que el unir géneros de discurso en un nuevo sistema ceremonial sentó las bases de la nueva identidad, ya que en el presente la participación en el sistema ceremonial es una de las señas de identidad marubo.

A comienzos de siglo XXI, los marubo siguen innovando. En 2009, por ejemplo, escuché debates sobre un nuevo formato ceremonial, la «fiesta cultural». Esta fiesta se organizaba con fondos de agencias gubernamentales e incluía novedades como potentes equipamientos de sonido eléctricos, bandas musicales no-marubo y reinterpretaciones teatrales de motivos míticos tradicionales. Algunos decían que, como no eran ceremonias tradicionales, representaban una destrucción de la cultura; otros respondían que a los jóvenes ahora les atraían más las discotecas de Atalaia que las fiestas tradicionales del interior, y para interesarles en la cultura tradicional había que presentarla en contextos que pudieran atraerlos tanto como la vida nocturna citadina. Así, la innovación ritual sigue vehiculando ideas sobre la identidad étnica y la manera correcta de ser indígena en el contexto del sistema mundial. También siguen usando todo su poder ritual, por ejemplo para enfrentarse a la atroz epidemia de hepatitis en el Yavarí (Coutinho 2008; CTI/ISA 2011), contra la cual los marubo usan no sólo los shõki para efectuar curaciones, sino también las reuniones para presionar a los órganos burocráticos para que establezcan un sistema de salud dentro del cual puedan acceder a las vacunas que deberían estarles protegiendo de la muerte. Los marubo siguen, así, usando toda la gama de formas ceremoniales y de discurso para sobrevivir y prosperar física y culturalmente ante la continua violencia estructural del sistema mundial.

\section{Referencias bibliográficas}

Cesarino, Pedro

2008 Oniska: A poética da morte e do mundo entre os Marubo da Amazônia Ocidental. Río de Janeiro: Museu Nacional, Universidade Federal do Rio de Janeiro.

COUTINHO JúnIOR, Walter

1993 Brancos e barbudos na Amazônia: os Mayoruna na história. Brasilia: Universidade de Brasília. 
2008 Hepatopatias no vale do Javari: virulento agravo à saúde indígena e afronta aos direitos humanos. Manaus: Ministério Público Federal, Procuradoria da República no Amazonas.

CTI / ISA

2011 Saúde na Terra Indígena Vale do Javari. Diagnóstico médico-antropológico: subsidios e recomendações para uma política de assistência. Brasilia: Centro de Trabalho Indigenista / Institutos Socioambiental.

EAKIN, Lucille, Erwin LAURIAULT y Harry BoONSTRA

1986 People of the Ucayali: The Shipibo and Conibo of Peru. Dallas: International Museum of Cultures.

ERIKSON, Philippe

1993 «Une nébuleuse compacte: le macro-ensemble Pano». L'Homme 33: 45-58.

1996 La griffe des aïeux: marquage du corps et démarquages ethniques chez les Matis d'Amazonie. París: Peeters.

FLECK, David

s.f. «Inventory of Panoan sections». Manuscrito sin publicar.

GraHAM, Laura

1995 Performing Dreams: Discourses of Immortality Among the Xavante of Central Brazil. Austin: University of Texas Press.

HyMEs, Dell

1974 Foundations in Sociolinguistics: An Ethnographic Approach. Filadelfia: University of Pennsylvania Press.

KeIFENHEIM, Barbara

1990 «Nawa: un concept clé de l'altérité chez les Pano». Journal de la Société des Américanistes $76:$ 79-94.

Kensinger, Kenneth M.

1995 How Real People Ought to Live: The Cashinahua of Eastern Peru. Prospect Heights, Illinois: Waveland.

Melatti, Julio Cezar

s.f. «Censo genealógico Marubo». Manuscrito sin publicar.

1977 «Estrutura social Marúbo: um sistema australiano na Amazônia». Anuário Antropológico 76: 83-120.

1981 Javari. Povos indígenas do Brasil, vol. 5: Javari. São Paulo: CEDI.

1986 Wenía: A origem mitológica da cultura Marubo. Trabalhos de Ciências Sociais, Série Antropologia Social, 78. Brasilia: Universidade de Brasília.

Montagner Melatti, Delvair

1985 O mundo dos espíritos: estudo etnográfico dos ritos de cura Marúbo. Brasilia: Universidade de Brasília.

Montagner Melatti, Delvair y Julio Cezar Melatti

1975 Relatório sobre os índios Marubo. Trabalhos de Ciências Sociais, Série Antropologia Social 13. Brasilia: Universidade de Brasília.

1986 «A maloca Marúbo: organização do espaço». Revista de Antropologia 29: 41-55.

RuEDAS, Javier

2001 The Marubo Political System. Nueva Orleans: Tulane University. 
2002 «Marubo Discourse Genres and Domains of Influence: Language and Politics in an Indigenous Amazonian Village». International Journal of American Linguistics 68: 447-482.

OAKDALE, Suzanne

2009 «Ritual and the Circulation of Experience: Negotiating Community in the Twentieth Century Amazon», en Ritual Communication, Gunter Senft y Ellen B. Basso, eds., pp. 153-170. Oxford: Berg.

WeINSTEIN, Barbara

1983 The Amazon Rubber Boom, 1850-1920. Stanford: Stanford University Press.

WelPer, Elena Monteiro

2009 O mundo de João Tuxaua: (Trans)formação do povo Marubo. Río de Janeiro: Museu Nacional, Universidade Federal do Rio de Janeiro.

WhitTen JR., Norman E.

2003 «Introduction», en Millennial Ecuador: Critical Essays on Cultural Transformations and Social Dynamics, Norman E. Whitten, Jr., ed., pp. 1-45. Iowa City: University of Iowa Press. 